Article

\title{
Beyond Wastescapes: Towards Circular Landscapes. Addressing the Spatial Dimension of Circularity through the Regeneration of Wastescapes
}

\author{
Libera Amenta 1,2,*(D) and Arjan van Timmeren 2,3,*(D) \\ 1 Dipartimento di Architettura, Università degli Studi di Napoli Federico II, \\ Via Forno Vecchio, 36, 80134 Napoli (NA), Italy \\ 2 Environmental Technology \& Design, Department of Urbanism, Faculty of Architecture and the Built \\ Environment, Delft University of Technology, Julianalaan 134, 2628 BL Delft, The Netherlands \\ 3 Institute for Advanced Metropolitan Solutions (AMS), Kattenburgerstraat 5 Building 27, \\ 1018 JA Amsterdam, The Netherlands \\ * Correspondence: 1.amenta@tudelft.nl (L.A.); a.vanTimmeren@tudelft.nl or \\ arjan.vantimmeren@ams-institute.org (A.v.T.); Tel.: +39-320-1435079 (L.A.)
}

Received: 8 October 2018; Accepted: 22 November 2018; Published: 12 December 2018

\begin{abstract}
Wastescapes are the result of unsustainable linear growth processes and their spatial consequences within the context of urban metabolic flows and related infrastructure. They represent the operational infrastructure for waste management and include Drosscapes, generating complex relations with the servicing and surrounding territory. In particular, the peri-urban areas are spatially affected by these processes. This often leads to ineffective use and/or abandonment because they are currently impossible to use, demanding impactful (and often expensive) regeneration and revalorization to make them usable again. Being part of the urban metabolic process, wastescapes are in a continuous state of dynamic equilibrium. They can be considered crucial areas from a metropolitan perspective because they have the potential to become innovative spatial contexts or resources in a Circular Economy $(\mathrm{CE})$, which aims to overcome the crises of both resource scarcity and spatial fragmentation. However, common and shared definitions of wastescapes are still missing at the European policy level, as only classical categories of material waste are generally mentioned. Wastescapes can be considered as 'potentiality contexts' where developing, testing, and implementing Eco-Innovative Solutions (EIS) can be done. By doing so, wastescapes can help start transitions towards a CE. This can be achieved by using Peri-urban Living Labs (PULL), which have the potential to be the virtual and physical environments in which experimenting the collaborative co-creation process for developing EIS can be done. Doing so will allow for the improvement of waste management and for the revalorization of wastescapes in collaboration with all potential stakeholders.
\end{abstract}

Keywords: wastescapes; circular economy; eco-innovation; sustainability; urban metabolism

\section{Introduction}

"Land is a finite resource" [1]. Our sprawling cities over the past couple of centuries have been shaped by the linear economy and its growth model, which are based on a unidirectional flow of 'use-consume-discard' and this is "pushing the planet's ecosystems to the limit" [2]. These economic systems are unfortunately based on the wrong assumption that resources and energy will never be depleted. They also require a continuous process of growth that erodes socio-ecological flows and impacts the limits of ecosystems. Consuming in this way exceeds the actual restricted availability of natural resources and compromises the capacity at which the planet can metabolize waste [2]. Even though a moment of change in the paradigm of growth is occurring, the contemporary industrial 
system and other growth systems are still based on unsustainable linear processes [3]. Within this context, countries from all over the world have been urged to adapt their political agendas in order to meet the United Nation's 17 Sustainable Development Goals (SDG) by the year 2030, an initiative which is related to people, the planet, and their prosperity [4].

An important aspect to consider in order to meet the above-mentioned goals is the availability of land as a resource. Since the turn of the millennium, urban expansion into natural and agricultural lands has been recorded in countries around the world, including China [5,6], India [7,8], Puerto Rico [9], and the United States [10]. For instance, China has the world's largest population (18.54\%) [11], but only $12 \%$ of its land is arable [12]. Between 1997 and 2008, agricultural land in China decreased by 1 million hectares due to urbanization, resulting in a production loss of ca. 8.2-9.8\% [13]. Negative trends in China's agricultural production potential are exacerbated by the fact that a sixth of its arable land is polluted by heavy metals, while another $40 \%$ is succumbing to the effects of desertification [12]. From a global outlook, urban expansion is expected to take place on soils that are 1.77 times more productive for cultivation than the global average [13] until the year 2030. This indicates that land which will be lost to urban expansion is of relatively high agricultural productivity, since much of the global urban expansion is predicted to occur in deltas, river valleys, and along shorelines. It is estimated that this expansion will, in turn, cause the global population to increase in these fertile areas [14], all while facing the uncertain effects of rising temperatures caused by global warming [15].

The perpetuation of the linear growth model is leading to issues of abandonment, dereliction, pollution, waste, and territorial vulnerability. This, in turn, influences the form of the contemporary urbanizations all around the world and increases its claim on these vulnerable soils. The seemingly endless consumption of resources that the linear economic model uses is raising new urban questions and environmental challenges to find a solution by looking at alternative sustainable and circular futures.

The problematic territories defined by such features could represent potential transitional realities, characterized by a dynamic equilibrium [16] under transformation processes. This leads towards 'deformed' landscapes, which can either be defined as wasted landscapes [17,18], or wastescapes [19-22]. The umbrella definition of wastescapes includes places such as abandoned territories, underused areas, former and polluted industrial areas, bare lands, and indefinite interstitial spaces, as well as the operational landscape and infrastructure of waste (management) [23,24]. The complexity involved with wastescapes deals with the notion that it includes many different fields of focus, making it a multidisciplinary topic. The term is associated with concepts related to economic, quality of life, health, accessibility, resources, society, landscape, environment, and infrastructure. The clustering of these terms helps to compose (peri) urban challenges, while offering valuable space(s) for finding solutions. For instance, the regeneration of wastescapes can eventually help support circular concepts by creating closed resource loops that produce little to no waste. Regeneration can also help in the development of a more vital city through the qualitative improvement of connections by physically increasing accessibility to existing urban infrastructures, as well as green and blue environments. Thirdly, the regeneration of wastescapes can help improve inter-network related connectivity, e.g., by ameliorating cycle or pedestrian networks of territories (Figure 1) [25].

In this paper it is argued that there is an urgency to declare a global restriction against urban encroachment on high-quality soils, and a need to repair and re-use existing wastescapes in order to halt the perpetual processes of autophagy: "a process of cellular self-digestion." Within the presented context, it refers to the phenomenon of resource depletion and reduction of prosperity of existing values [16]. The paper also focuses on the dilemmas of global open access, investigating the trade-offs of the spatial, temporal, and social dimensions of contemporary urban growth. By doing so, predictions are made on the capacity at which food security can be provided by comparing healthy soil and living environments of today with the future. 


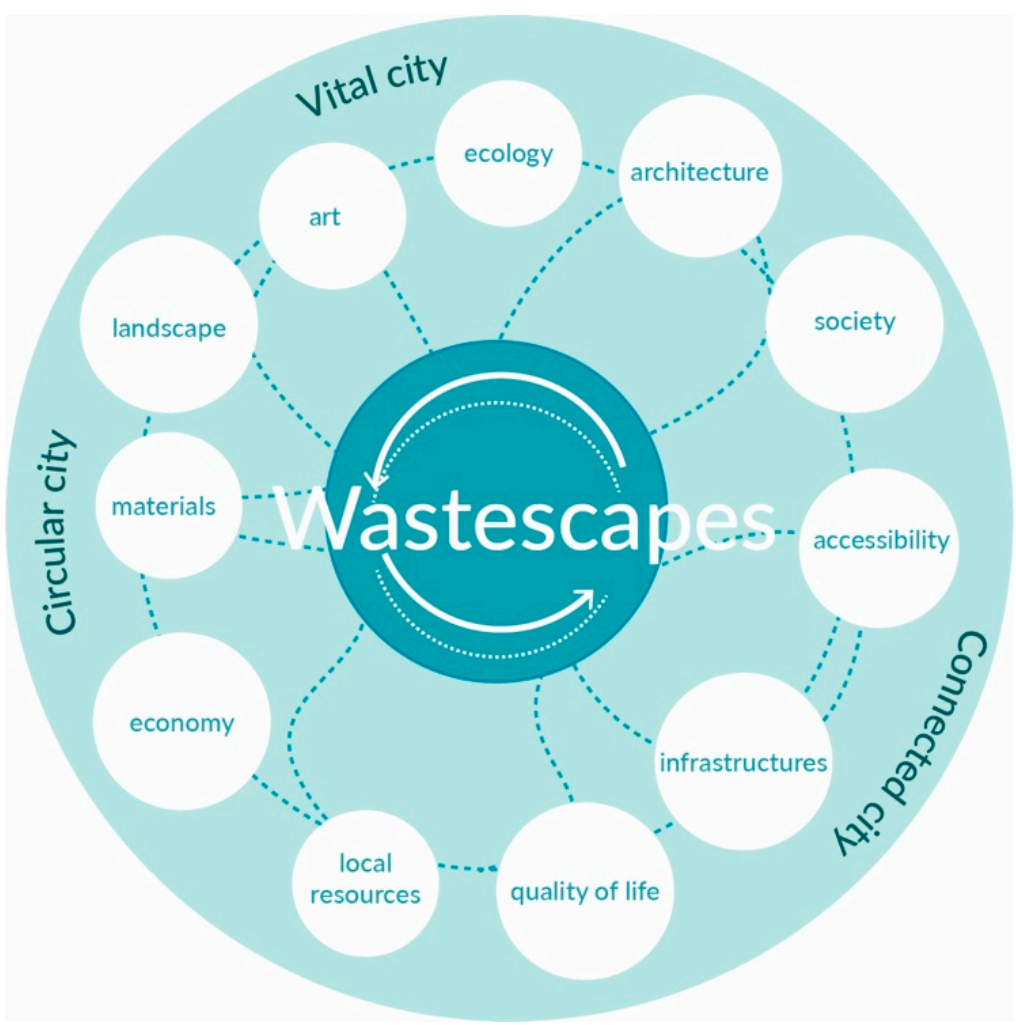

Figure 1. The regeneration of wastescapes can lead to a circular, vital, and connected city.

In addition, this paper investigates the spatial effects of waste and wastescapes as the natural outcomes of urban metabolic processes in contemporary territories [26-30]. The effects and impacts of the different types of waste flows on the territory are studied in relation to wastescapes, particularly for two pilot cases: the metropolitan region of Amsterdam in the Netherlands, and Naples in Italy.

The research involved in the investigation process presents the concept of Urban Living Labs [31] as environments where a common understanding of wastescapes can be investigated by key stakeholders. In turn, this will help in identifying Eco-Innovative Solutions [32,33] for their regeneration. The innovative and inclusive setup of a sequential series of Living Lab (meetings and workshops), based on a proven methodology, provides a framework to develop (iterate/validate) proposals for guidelines towards pan-European policies. Doing so will allow for focusing on an integrated approach for the regeneration of wastescapes, while including new possibilities of temporary and flexible uses.

\subsection{Aims and Relevance}

"Soil resources in many parts of Europe are being over-exploited" [34]. Despite the fact that soil resources are limited, they are often misused, polluted, or eroded [1]. A responsible and sustainable use of virgin resources is still not always the case, with consumption processes too often resulting in environmental depletion. Therefore, this paper aims to contribute to the promotion of measures to prevent environmental damage, to recover compromised territories, to improve sustainability, and to achieve more healthy cities.

For reasons previously stated above, it is important that vacant, abandoned, or polluted lands be kept to a minimum. It has been proven that there is a correlation between the presence of vacant lands and the negative impacts of their perception on both the mental and physical health of the citizens affected by them [35]. For this purpose, existing cities need to improve their livability and overall health by following more sustainable growth models [36], "by improving the physical and social environments of cities" [37] (p. 431). 
Existing (non-planned) cities are characterized by structural complexity, referred to as a semi-axiom grid (Figure 2) [38]. In the areas between the urban and rural, the so-called peri-urban territories [39-41], it is possible to identify several kinds of landscape remains that can be seen as wastescapes [42] - it is even possible to find these remains in urban cores. Most of these cases are the result of processes in the linear economy, as well as the planning of urban landscapes which are based upon the separation of functions through space(s). This is why studying these issues of wastescapes is relevant, since it deals with an important part of the main challenges (including solutions) of today's cities:

1. Environmental challenges [43]: in most of the cases they are polluted, compromised, consumed, or uncovered/empty/unproductive soils.

2. Landscape-related challenges [44]: they are territories not spatially connected or integrated into the surrounding landscape, resulting in isolated or disconnected fragments which are often perceived as ugly.

3. Management challenges: lack of flexibility in policies/regulations and implementation of existing policies that often result in abandoned lands which nobody takes care of.

4. Societal challenges: often wastescapes are related to conflicts—or of former conflicts—such as confiscated assets, illegal or informal constructions, and/or sites of illegal waste dumping.

5. Economic challenges: lack of funding for their regeneration and a lack of economic business models that break through the state of abandonment or underuse of wastescapes, while opening up new ways to achieve profit (not necessarily being economical).

6. Perception challenges: wastescapes represent inaccessible, abandoned, and often dangerously polluted areas for the inhabitants that encounter them in their daily routines. This is a problem from a perspective point of view due to the visual impact generated by the wastescapes. Moreover, they are perceived as unsafe areas that host criminal activities, negatively affecting life satisfaction of the inhabitants [35].

7. Knowledge/awareness challenges: a shared knowledge and a common understanding of waste and wastescapes as actual resources for developing site-specific Eco-Innovative Solutions is absent at both political and institutional levels.
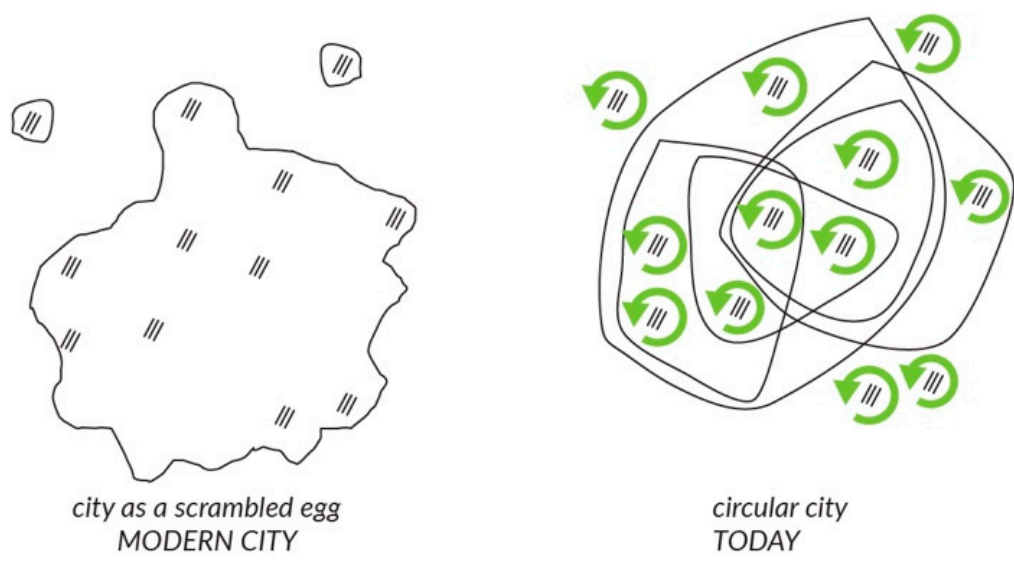

Figure 2. Creative update on the diagram by Cedric Price entitled "The city as an egg", (in today's cities, there is the need to work on the existing fragments of the scrambled modern city applying the principles of circularity), and of the diagram of the semilattice, retrieved from the publication "A city is not a tree" by Christopher Alexander. Source: Cedric Price; Christopher Alexander. Graphic adapted by the authors.

From a flow-based perspective, the ongoing processes of urbanization are often still dependent on increasing the throughput of water, material, and energy flows, in order to satisfy the growing 
concentration of new demand within the urban fabric [2]. The extreme population growth in cities has resulted in the degradation of ecosystems, habitat loss, greenhouse gas emissions (GHG), climate change, and environmental pollution. Earth's capacity for sustaining human life is limited by sun-fall, biologically produced oxygen, biomass production, and pollution absorption capacity. These are all aspects which are strongly related to space. At the moment, humans are consuming the equivalent of 1.7 Earths [45] in order to provide resources and absorb pollution (including carbon dioxide). Over-consumption is still possible because of these inherited resources: fossil fuel, fertile land, clean water, and even oxygen in the atmosphere. The act of converting renewable resources into waste faster than waste can be turned back into resources is termed as 'global ecological overshoot' [46]. The actual global ecological overshoot is a wake-up call for immediate action by city planners to change the course of urban metabolism and its flows. There is a need for a regeneration of wastescapes as it directly relates to issues of metabolism and the scarcity, misuse, and exploitation of virgin resources. Finding sustainable alternatives for land use will be necessary in order to transition cities towards circular economies and metabolisms. Within this context, a renewal process will generate significant territorial value, especially if we consider the scarcity of soil as a non-renewable resource [47]. The fact that soil functions need to be preserved because of their environmental and socio-economic values [48], supports the need for circular regeneration of these territorial resources themselves. Moreover, studying the impact of waste flows on territory also implies the need to address how operational infrastructures of waste are related. Relationships that need to be looked at involve the spatiality and functionality of waste flows to territory and their related (local) resources, while also considering the consequences of this for the territory itself.

\subsection{Contribution to Knowledge}

A clear and shared perspective on wastescapes is still missing in literature, therefore resulting in the term to still be considered an experimental concept. This paper aims to bridge this knowledge gap by proposing a new taxonomy to define wastescapes. However, the purpose of doing so is not just an exercise of nomination. The paper also aims to address the existence of abandoned or polluted large industrial zones, as well as on small, scattered areas in decline-within urban and peri-urban territories [49].

Despite of all of this, the topic of wastescapes is not a new one, as a large body of literature (mostly related to regeneration) does exist. However, the presented elaboration though is still nascent: a circular and systemic way of regeneration of wastescapes, with the inclusion of urban metabolic processes. The novelty of this presented strategy relates to a circular metabolism approach $[19,50]$ that exists in order to "reduce consumption and pollution, recycle, and maximize renewables" [50] (p. 11). This will be achieved within the setting of Urban Living Labs (ULL) [31], which will involve all relevant stakeholders in collaborative workshops. The aim of these labs is to help the construction of circular solutions for the repurposing of wastescapes.

Many disciplines merge when addressing wastescapes, such as architecture, landscaping, and planning. This rings true because these disciplines include ecological, environmental, and social aspects which combine with technical, socio-cultural, and even political aspects [51]. Wastescapes often are compromised areas, from both ecological and environmental points of views. They are also often difficult to be managed by public authorities, either because there is a lack funding for their regeneration, or because they are private proprieties. Therefore, multidisciplinary and multi-stakeholder processes and partnerships [52] are key to redeveloping wastescapes. They are a major part of the decision making process in order to solve today's complex challenges [53].

For the management of wastescapes, the role of both public and private actors is crucial to their regeneration. Their perception of the value of investing in the regeneration of wastescapes, and the knowledge of the potential added value that such regeneration creates, are still not widely shared or known. 
In order to overcome this situation, there is the need for co-operation between top-down and bottom-up approaches that integrate short and long-term transition strategies. These strategies, therefore, need to be in line with the current policy initiatives and principles which promote European countries and cities within their borders to transition towards a Circular Economy [54].

\section{Understanding Processes and Phenomena}

\subsection{When Does a Place Become a Wastescape?}

In the transition from the modern to the contemporary city, and within the contemporary cities' dynamics themselves, most wastescapes are the result of low-density urbanization processes, and of shrinkage of economic activities in specific areas. These processes result in aged industrial areas that have either approached or entered their end-of life and can be found either in a phase of decline, dereliction, and/or abandonment. A majority of wastescapes also tend to emerge in peri-urban areas, which can be considered as fragile areas of our cities, and are territories that are not entirely urban nor rural $[39,55]$. Peri-urban areas are defined by scattered dispersed settlements $[40,56,57]$ which can also be defined as 'territories in-between' [41]. These peri-urban fabrics display an "actual complex morphology of built and unbuilt land, mix of functions, and the connecting and separating effects of infrastructure" [41] (p. 62).

In our territories, 'growth' and 'decline' exist together as pairs [58]. Territories that enter phases of decline tend to display a combination of abandoned buildings which exist with public, semi-public, and private spaces that sit desolate and empty. The contemporary city includes varied phenomena that are united by similar problems: among them are urgent environmental and ecological issues that pose new challenges for the city. These problems need to be addressed through responsible experiments that works on transforming the city through practices of reuse [58]. Different cycles, processes, and stakeholders (public/private) are involved in these processes of abandonment, often generating second-order effects such as physical dereliction at both larger scale levels and in related areas (decline of services, demographic disbalance, etc.). Material-waste cycles also generate wastescapes: these cycles are related to both legal structures in place, and to informal waste related actions of the city (e.g., illegal abandonment of waste along infrastructure networks in the case of Naples). In addition to these spaces, specific functional entities or infrastructures could also enter a stage of malfunctioning that results in abandonment of places such as former industrial and (city embedded) port areas. The appearance of these wastescapes in these cases are in a so-called 'waiting condition', but in some other cases, already all kinds of bottom-up initiatives and developments have evolved to repair them.

\subsection{Definitions of Wastescapes}

It is essentially important to have a clear and unambiguous description of wastescapes [21] that can systemize the approaches of their regeneration from many different perspectives, such as environmental and landscape preservation, artistic, economic, et cetera. This paper aims to facilitate the work of decision makers to operate a systematic selection of eco-innovations $[32,59,60]$ for wastescapes regeneration. By extracting common parameters, categories of wastescapes were identified, which in turn helped define the criteria to objectively define, categorize, and map wastescapes. A shared interpretation of wastescapes offers practitioners and decision makers a clearer outlook towards finding an effective toolkit to address the above-mentioned related problems. Nevertheless, at all times, a site-specific roadmap for the regeneration of wastescapes will be needed for each case-study. The improved management of these neglected spaces can only be secured through a systemized, yet customized approach that increases their relations with the urban and metabolic dynamics of the larger territory.

This research, therefore, proposes a more comprehensive concept of waste (or resources), adding the territorial dimension of wastescapes to the common classification of material waste, which is still missing at a European policy level. It is because of this that wastescapes are actually 
considered to still be a developing concept. In fact, wastescapes are sensible to specific (local) social, economic, and environmental contexts.

Wastescapes are defined as parts of landscapes going through a linear transition from valuable, accessible, public and natural landscapes, towards a variety of impacted areas involving wastefulness, inaccessibility, social/environmental degradation, and 'decreasing natural value' [22] (p. 13). In addition, this research proposes to understand wastescapes as "enabling contexts" [22,61-64] for circular regenerations. This approach finds its foundation in the work of Kevin Lynch "Wasting Away" [65]. In his work, waste is considered to be both the "dark side of change" and the natural outcome of growth. In the same way, wastescapes, as an extension of the waste concept, can hide possibilities for redevelopments and therefore for positive changes.

More recently, in 2006, Alan Berger developed the concept of Drosscape for American territories [44]. This paper also builds its analysis on this concept, adapting and specifying it for European contexts. Berger couples the two terms "dross", a term that conveys loss and dissipation, with "scape," which embeds the dimension of landscape as a potential kind of waste. He highlights the importance to also consider the discarded areas as part of our daily landscapes, which is in line with the European Landscape Convention of 2000 [66]. In addition to this, attention has been given lately to the notion of operational landscapes [67], and to the infrastructures and related geographies of waste and trash [68].

In line with Lynch, this research returns to underline the positive value of these spaces by combining "waste" with the word "scape". This is done to create a starting point for change related to waste (or resource) management in the urban landscape. In this sense, wastescapes can be defined as the 'potentiality, or enabling of contexts' in which the developing, testing, and the implementation of place-specific Eco-Innovative Solutions (EIS) [22] (p. 184) can take place. This adapted notion of wastescapes includes the following two characteristics:

- 'Waste', on one hand, is related to resources, which include unused objects, substances, and/or material flows that cross territories that define the urban metabolism.

- 'Scape', on the other hand, is based on spatial characteristics and the claim that such flows seize on territory and/or landscape. Using the concept of landscape makes it possible to start transition strategies towards a circular urban metabolism at a geographical location that helps create spatial proximity and (co)relations.

In a way, wastescapes can often be interpreted as the outcome of the process of linear and extensive growth. They also concern scattered spaces which are often related to infrastructures (and/or related nuisance zones) that represent different misfits or challenges [21].

As shown in Figure 3, wastescapes can be characterized by different environmental values. These values could be indicated by multiple factors such as: low degrees of biodiversity, certain types of biodiversity loss, and unused or underused areas with certain challenges related to livability or quality of life. Moreover, it should be considered that wastescapes could be the outcome of simultaneous processes of deindustrialization, Post-Fordism, and technological innovation [22,44].

\subsection{A Twofold Concept}

This section is an attempt to elaborate further on how the previous section presented a twofold definition of wastescapes. The first level of definition is related to the general notion of wastescapes, including the all-embracing characteristics that are not strictly related to one specific case study (Figure 4). The second is a more specific and clustered elaboration of the definition, including a list of possible spaces that can be a result of this interpretation. The latter has been tested in practice in the case studies of Amsterdam and Naples [22], and they seem to cover a wide array of possible categories in these case studies.

Wastescapes can be places that have lost their identities [69], or can be referred to as areas of 'the Third Landscape' [70], which are places where biodiversity reserves take over. Furthermore, 
these places can be uncultivated areas and/or vacant soils that are not anymore suitable for agricultural purposes, characterized in this case by biodiversity loss due to the different form of pollution [71].

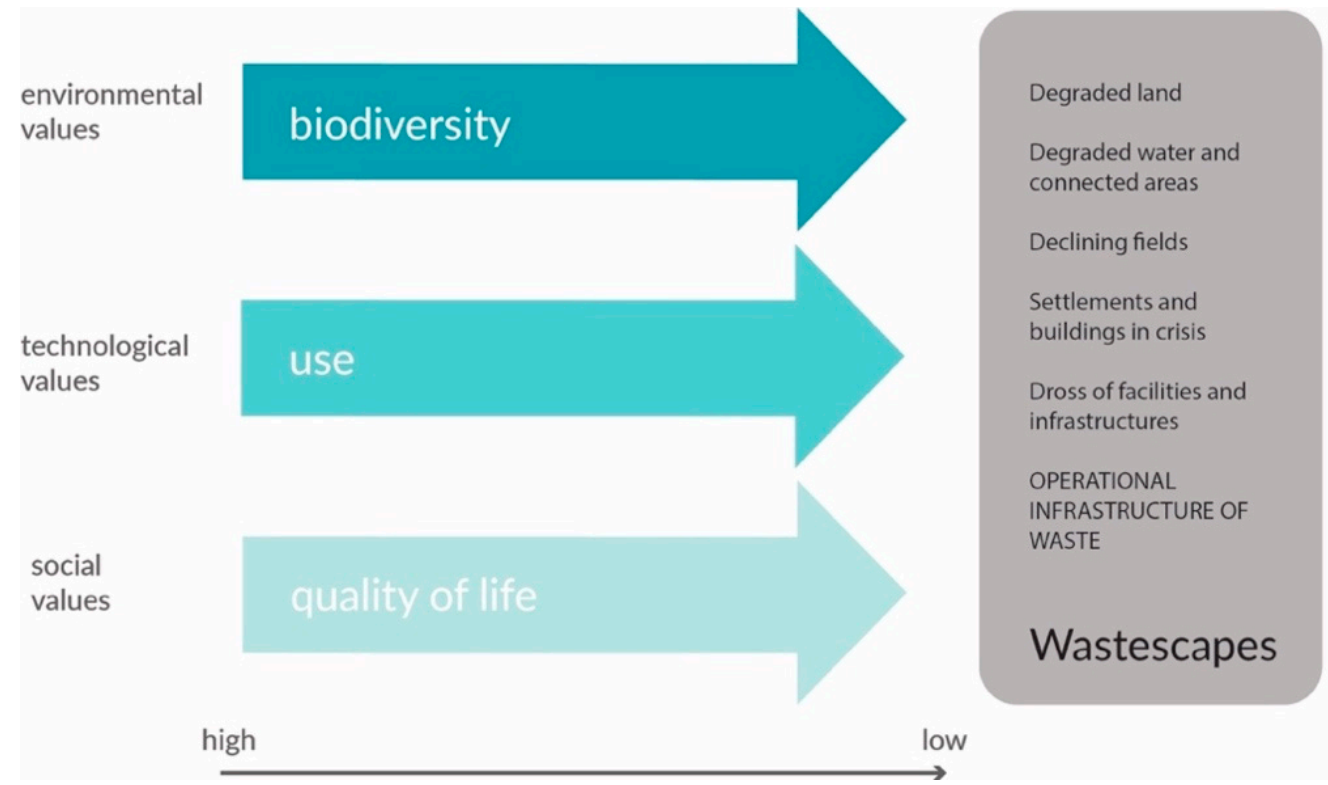

Figure 3. The current linear state of wastescapes, characterized by a decrease of environmental, technological, and social values.

Wastescapes are also complex territories that can be defined by several characteristics which can be the result of crises dealing with certain life cycles or processes (e.g., post-industrial areas) that often includes pollution. Wastescapes are a result of a long period of abandonment which often have reduced or denied accessibility, due to a lack of knowledge, ownership, and/or funds to regenerate them. On a positive note, however, there are several examples where these abandoned spaces are characterized by valuable ecologies, with a high degree of biodiversity.

The concept of wastescape regeneration embraces the landscape's opportunities and territorial conditions, and can be clustered in six different categories [21,22]:

1. Degraded land, impoverished from the point of view of soil fertility, due to human activities;

2. Degraded water, including both properly polluted or compromised water bodies, and territories under hydraulic pressures;

3. Declining fields, consisting of on vacant/under-used and abandoned fields, vacant parcels, and vulnerable soils;

4. Settlements and buildings in crisis, comprising vacant/underused, neglected, or obsolescent buildings and settlements, as well as the illegal/informal ones;

5. "Dross" of facilities and infrastructures, including dismissed or underused infrastructures and facilities;

6. Operational infrastructure of waste, related to waste management facilities, such as incinerators and landfills.

As stated before, these categories are the result of a recursive process carried on within the two pilot Peri-Urban Living Labs of Amsterdam and Naples. These Living Lab environments support a better understanding of wastescapes that envisions the necessity to agree upon a new and common vocabulary that is not only capable to comprehend but is also capable to manage and redesign the complexity and uncertainty of these landscapes. 


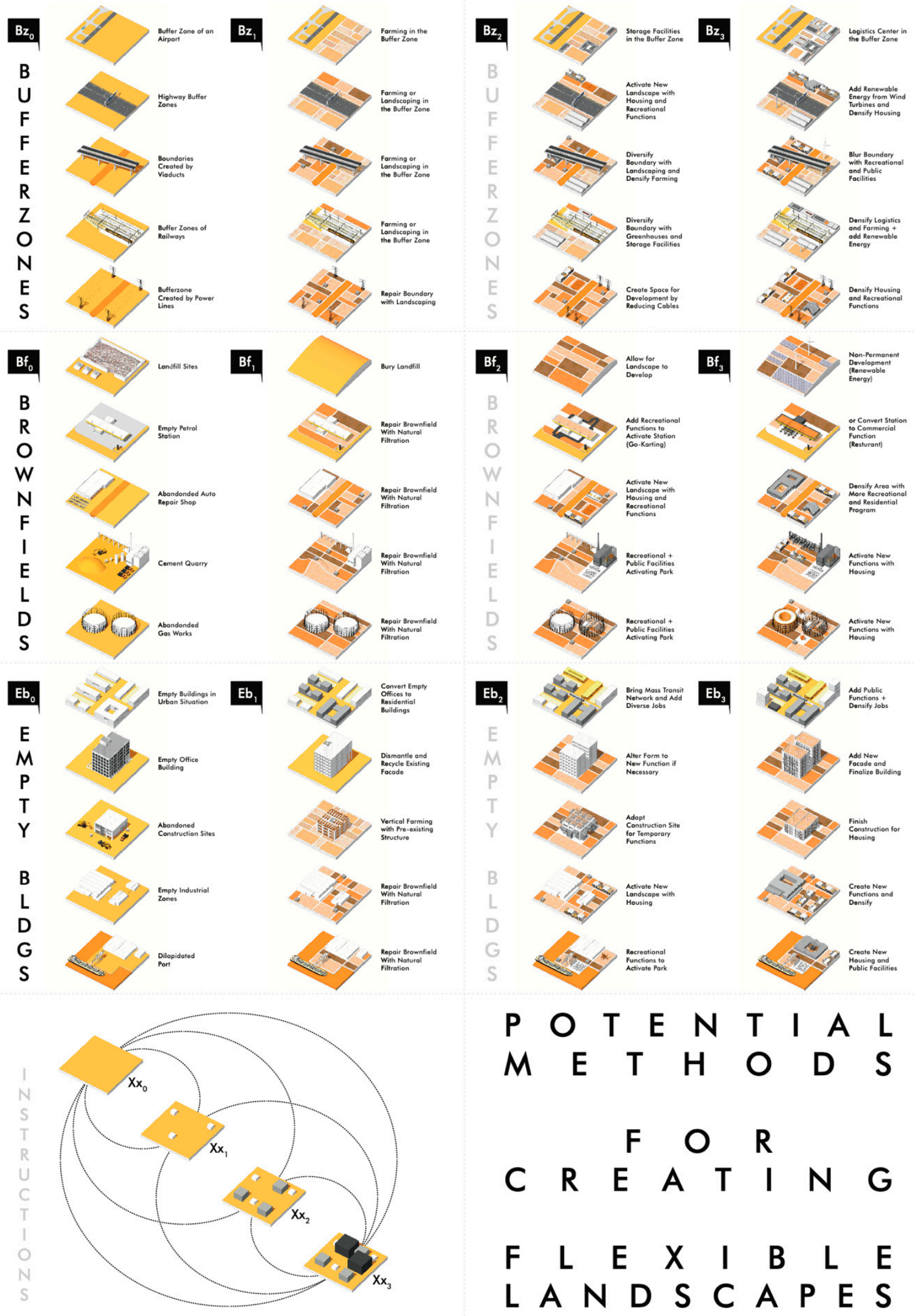

Figure 4. Potential methods for creating flexible landscapes. Graphic by: Anubhuti Chandna, Danny Janse, Gwenhwyfar Spil, Jingxuan Xie, Osman Ural. 
As wastescapes connect both material, territorial dimensions, and spatial implications of resource flows, it is important to consider their regeneration within the framework of a transition towards a Circular Economy (CE) [19,72]. CE implies a rethinking of society towards closed loops of resource use, creating an economy in which there is no waste in industrial process chains. CE aims to shift the focus away from products and more towards processes [73]. This could be a challenge, however, as decision makers could encounter difficulties in the implementation of Eco-Innovative Solutions (EIS) to support $\mathrm{CE}$ principles. It is not easy to change the ruling paradigms and growth paths [74] of current economic systems and production models. Within this context, wastescapes should be investigated at multiple and different scales:

- The complexity of the topic asks to go beyond administrative boundaries: both in the governance and decision-making processes, as well as spatially. In the process of mapping wastescapes, there is a need to overcome municipal boundaries in order to understand the regional implications of their formation and potential regeneration.

- The governance of wastescapes is complex and complicated, due to the multiplicity of actors that affect(ed) and generate(d) them. Very often, these actors (have) only work(ed) in a sectorial way, therefore lacking the perspectives of integration and cooperation.

- The local scale is key. In particular, its role in larger contexts in relation to the previously mentioned 'enabling contexts' [22] in which the processes of regeneration need to be realized, as well as the effective applications and developments of eco-innovative solutions and strategies.

- Looking at multiple and different scales will support the identification of transferable strategies and solutions, which will, in turn, enable the scale-up and transfer of methodology to other cases.

In specific cases, there can be a 'path dependence' [75-77] which causes a continuation of linear models of urban growth in which stakeholders often are locked-in. These specific cases can also apply to wastescapes that have been in a condition of waiting for long periods of time. Particularly in these cases, the application of Urban Living Labs $[20,33]$ can help to break up this status quo by bringing together different stakeholders in a legal setting that would foster the co-creation and development of joint Eco-Innovative Solutions [59]. Doing so will establish models for change, while responding to specific challenges and related objectives identified during workshops sessions. This will allow for both tangible and intangible relations with various flows (people, goods, waste, etc.) that can be broken or compromised in different ways.

The characteristics of wastescapes can both be objective and measurable, depending on the level of contamination, soil biodiversity, health of cities, and so on. Non-objective and qualitative aspects related to socio-behavioral matters regarding the perception and quality of public space, noise, odor, and etc. can also be measured when determining the character of wastescapes [21] (p. 23).

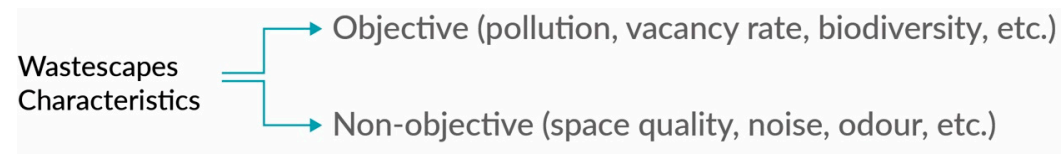

Wastescapes components can be both manmade, such as buildings and infrastructures, as well as natural, like for instance (polluted) soil, (polluted) water, vegetation [21] (p. 23).

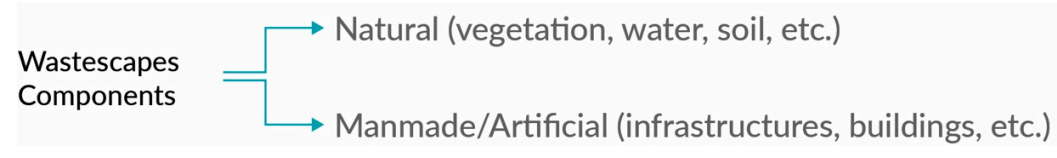

Developing Eco-Innovative Solutions (EIS) for wastescapes can help decision makers to connect the quantitative aspects of these places to their qualitative characteristics, as well as to try to include both natural and manmade components. This will allow for decision makers to overcome practical problems related to the aim of achieving a transition towards more circular solutions [59]. 


\subsection{Circularity As Part of the Regeneration of Wastescapes}

Due to its complexity, introducing and achieving circular regeneration of wastescapes is an innovative and extremely vulnerable (long-term) process. By addressing wastescapes, the depletion of natural and virgin resources can be prevented if the preservation of biodiversity and ecosystem services are done well [78]. Doing so will also help achieve one of the targets set by the European Commission for 2020 by "halting the loss of biodiversity and the degradation of ecosystem services in the EU by 2020, and restoring them in so far as feasible, while stepping up the EU contribution to averting global biodiversity loss" [79] (p. 6).

Although land scarcity and environmental damage are perceived as urgent matters in Europe, and much discussed internationally [80], there are major hindrances that prevent us to move towards the regeneration of wastescapes. This is due to decision makers lacking preparedness, and sometimes willingness, to be able to address this problem in the two case studies analyzed. From a systemic point of view, the application of integrated strategies is lacking because of the complexity and place-specific character of wastescapes. The delimitation and mapping of wastescapes, as well as developing regeneration strategies, requires a combination of continuous methodological iterations with the involvement of all local stakeholders and experts. As methods to repair wastescapes are multi-scalar in nature, regeneration processes should involve stakeholders which represent all relevant scales. In other words, scales and boundaries of wastescapes should not be limited by municipal or administrative borders. In fact, the inclusion of larger contexts is necessary in order to comprehend the interrelations of wastescapes within their wider territories. However, the various scales of authority could create an obstacle for the availability of stratified data, as wastescapes cross different territories that often include several municipalities in which different types of information are available. It is because of this that different approaches might be needed in order to overcome issues of data access at both multi-scalar and multi-territorial levels.

The presented research states that the main starting point of repairing wastescapes should be a focus on urban biocycles that potentially help improve soil regeneration and biodiversity. Doing so will allow such regenerations to help with the transition of society towards a Circular Economy. The research of repairing wastescapes (Figure 5) also allows for the exploration into the value of post-use urban nutrients and biomass, which can be achieved by regaining nutrients and releasing them back to the soil through available technologies [81].

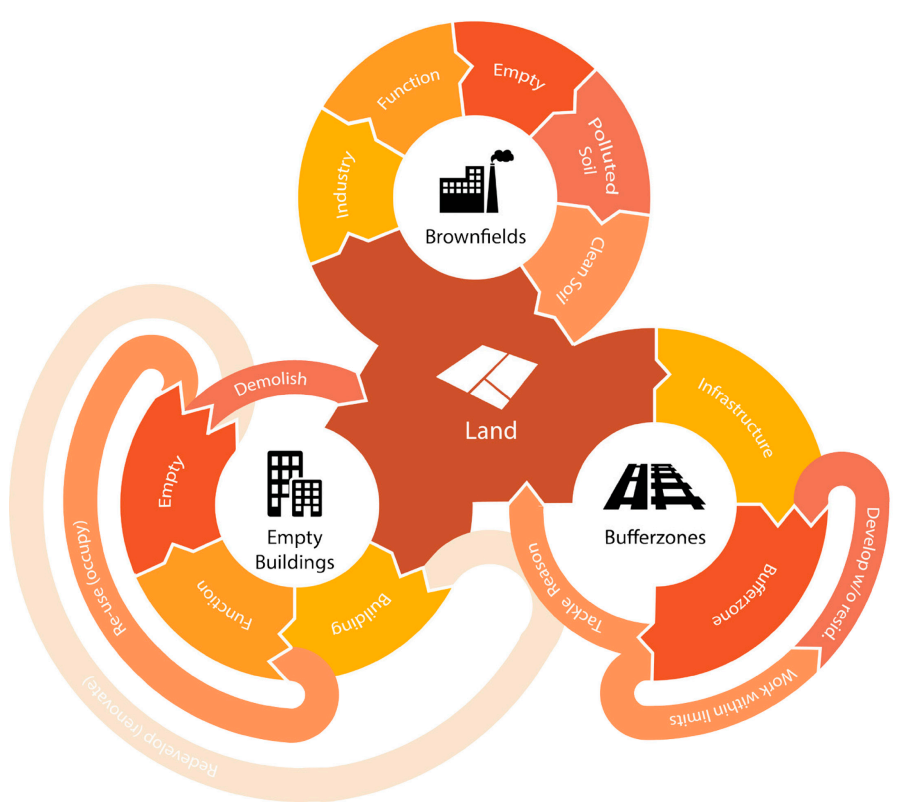

Figure 5. Making Land Circular. Graphic by: Anubhuti Chandna, Danny Janse, Gwenhwyfar Spil, Jingxuan Xie, Osman Ural. 


\section{Eco-Innovative Solutions for Wastescapes in Peri-Urban Living Labs}

\subsection{Eco-Innovative Solutions for Wastescapes}

The European Commission defines Eco-innovation as "any innovation resulting in significant progress towards the goal of sustainable development, by reducing the impacts of our production modes on the environment, enhancing nature's resilience to environmental pressures, or achieving a more efficient and responsible use of natural resources" [59]. In line with this approach, Eco-Innovative Solutions (EIS) for waste (scapes) intend to modify this way of thinking, and the human behavior related to resource consumption, waste production, and management: "Eco-Innovative Solutions are creative and smart ideas aimed to innovate and improve a specific and fixed process in relation of the management of waste as a resource and Wastescapes" [33] (p. 12). EIS can, therefore, be considered to be potential drivers for a more sustainable and circular model of growth within (peri-)urban areas. It is for this reason that in this research, a co-creation process is applied within the Peri-Urban Living Labs (PULLs) [33]. This process is used to enable and develop multiple sets of EIS that involve wastescapes, allowing for the support of sustainable urban developments that face the challenges of complex systems [82].

EIS are defined by a framework that considers different queries which would eventually match with the necessary requirements of a developed tool. A Geo-design Decision Support Environment (GDSE) [83] could be a tool in which the queries can be validated. For example, parameters that would need to be specified could be the stakeholders involved, the scales of application, goals, (reduced) impacts, etc. These criteria would be evaluated according to a process called PESTEL analysis [84]: Political/organisational (P), Economic (E), Social (S), Technical (T), Environmental (E), and Legal (L).

In a series of PULL meetings and workshops, the EIS were identified and elaborated in joint sessions with stakeholders. In advance to these PULLs, design workshops within university studios and other related teaching activities, analyses, and suggestions for promising EIS were made [33]. In most cases, EIS for the recycling of wastescapes involves environmental, health, and safety benefits. EIS can also help to make choices that will save virgin resources from being overexploited (e.g., soil, construction materials, et cetera). For instance, wastescapes can be compromised areas or existing and underused infrastructures. EIS for these areas can be implemented by using them for the storage of Construction and Demolition waste materials (C\&DW) waiting for reuse-considering buildings as material banks. These areas could also be used to make room for other separation, reuse, recycling, and/or upcycling related processes. For the EIS focusing on wastescapes regeneration, the following appeared to be conditional; they should:

- ensure value creation;

- meet stakeholders' needs;

- be based on and inspired by nature;

- foresee resilient and sustainable settlements;

- increase individual and social well-being.

\subsection{Peri-Urban Living Labs (PULLs) as Instruments for Developing Eco-Innovative Solutions}

The research presented in the six peri-urban areas (two lead cases and 4 fellow cases) resulted in a need for more sustainable management of waste (scapes). There is a need for them to be considered as innovative resources which will provide better accessible public spaces, improve biodiversity, enhance ecological values, and to generally achieve an overall improved quality of life. The specific objectives and challenges related to waste flows and wastescapes are addressed in the co-creation sessions of the PULL workshops, with the co-operation of all the stakeholders, in order to move towards circularity in peri-urban areas [20,31].

PULLs are defined both as environments to develop innovations [85], as well as workshop sessions where stakeholders actively participate in the co-creation of innovative services or products [86]. 
Amsterdam and Naples are the lead cases where the PULL workshops took place, and where the first Eco-Innovative Solutions are defined in co-creation environments. The methodology applied within the lead cases [33] is based on a quadruple helix model that is structured by a partnership that includes representatives from sectors of government, industry, academia, and the general public [87]. The PULL methodology consists of five phases: co-exploring, co-design, co-production, co-decision, and co-governance (Figure 6). The Eco-Innovative Solutions which resulted from the PULLs addressed a more circular functioning of peri-urban areas, due in part to unusual decision processes based on co-creation principles, and acknowledgement of the feeding in of new products and services [20].

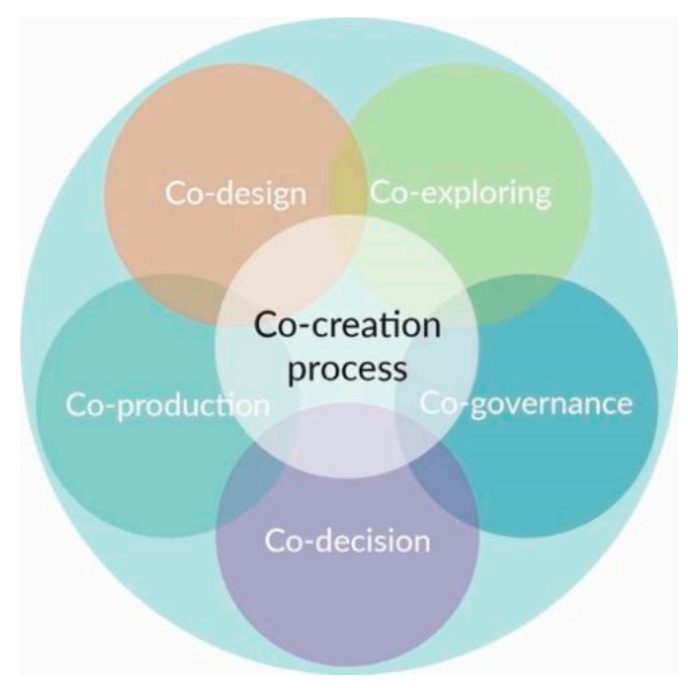

Figure 6. Co-creation process in Living Labs.

A similar setup was implemented in the other four European experimentations of Peri-Urban Living Labs [87], which were used as iterations and validations for the outcomes of the two lead cases. The actors' in PULLs are encouraged to join forces in order to understand the complexity of their urban challenges better and achieve more integrated solutions by including systemic changes that will not be limited by societal (sociopolitical, economic), legal, or technical thresholds. All of these issues should be considered at all times, within agreed objectives of waste (scape) prevention and waste (scape) valorization as an innovative use of resources. In contemporary cities, these areas are understood as "spaces for innovation" [88] (p. 38), from which the applied concept of decoupling urban growth from resource depletion can be a practical tool to improve the functionality of urban metabolism [88]. Through the identification of dedicated EIS for the transformation of wastescapes in these PULLs, wastescapes could potentially be developed as circular landscapes in which material and immaterial resources can be reused or recycled locally, with all kinds of (new) embedded values within them.

\subsection{Case Studies}

The most vulnerable spaces of the peri-urban territories in the two lead case studies of Amsterdam and Naples were identified. These are spaces where both waste management related challenges (at larger scales) and wastescapes are emerging problems.

Starting from the case study of Naples, the topic of wastescapes was first shaped and developed. In the Metropolitan Area of Naples, problems related to wastescapes are urgent because social problems are strictly interwoven with informal—and sometimes illegal—activities related to waste management, which end up generating complex geographies of waste. The first experiments done in the case of Naples to identify and map wastescapes have been further applied and verified in the case study of Amsterdam by building on the idea that the conceptual methods of Peri-Urban Living Lab (PULLs) are transferable to other cases [33]. This is stated in the previous chapter, combined with necessary place-specific focus shifts. In the case of Amsterdam, for example, one particularly local and unique 
characteristic was found necessary to be considered: clusters of marginal areas located around the boundaries of large infrastructures. These areas exist as leftover spaces within the noise nuisance zones of Schiphol Airport.

The research done in both the pilot cases of the Amsterdam Metropolitan Area and in the Metropolitan Area of Naples resulted in different, but very specific wastescape variants being identified as crucial issues that need to be further analyzed within the structure of the PULLs.

First of all, a draft mapping of wastescapes in the two case studies were made and discussed during the PULLs workshops. The maps were then updated and based on the feedback collected within the mixed teams of researchers and local stakeholders. This process of mapping was done in different sessions repeatedly so that all relevant wastescapes could be identified.

Next, within the PULL workshops, specific local challenges and the related objectives to overcome their current situation were identified through a participative group process. All stakeholders who participated in the PULL workshops were involved in the precise framing of the challenges and objectives, with the latter being ranked in accordance to the stakeholder's preferences. By doing so, the participants of PULL were empowered, because they felt had ownership of the developed solutions, and therefore minimizing possible conflicts between them [33].

Finally, in the design workshops done by university studios and other related teaching activities, analyses and suggestions for promising EIS were prepared [33]. The most promising were introduced in the discussion within the PULLs with the participation of the stakeholders. Here, the development and refining of the EIS for the case studies of Naples and Amsterdam took place. All shared ideas were cultivated together with the inputs of the stakeholders' feedback and inputs from the previous workshops, which included desktop research, researcher's meetings, students' works, and literature reviews.

\subsubsection{Wastescapes in the Metropolitan Area of Naples (MAN)}

In the pilot case of the Metropolitan Area of Naples, wastescapes are the result of complex processes which include illegal practices related to waste disposal. Wastescapes appear with different features within the focus area of the MAN, which is made up of 11 Municipalities: Naples (Ponticelli, Barra, San Giovanni a Teduccio), Casoria, Afragola, Acerra, Caivano, Casalnuovo, Crispano, Cardito, Frattaminore, and Volla e Cercola. According to the discussions among the various stakeholders that occurred during the different PULL meetings and workshops in Naples [89], there is a need to focus mostly on the challenging peri-urban areas around the high-speed train station of Naples-Afragola. This is because of the locations great potential for developing diverse Eco-Innovative Solutions.

The Focus Area is located at the edges of the compact city, and it is characterized by illegal activities that are produced by a combination of territorial 'fragmentation' and a low quality of life. In the PULL workshop in Naples, the topic of resource management, in relation with the main flows of construction waste, demolition waste, and organic waste, was addressed with a strong reference to wastescapes [33].

After the first interactions of the PULL workshops, a sample area (Figure 7)—at a more detailed scale- had been delimited within the boundaries of the larger focus area selected in the Neapolitan case-study. One of the main reasons why this area was selected is because the general challenges of the focus area are concentrated there. Secondly, the most prominent examples of wastescapes are there. Moreover, the sample area identified is of a great interest of the stakeholders present in the PULL workshops [22]. For this sample area, wastescapes had been identified and mapped, thanks to specific knowledge brought by the citizens, the public authorities, and the researchers that convened in the PULL workshops. This resulted in the realization that the main challenges related to wastescapes in the Metropolitan Area of Naples (Figure 8) are related to wastescapes in the High-Speed Train development areas that exist in the territories of Afragola, Acerra, and Pomigliano d'Arco. 


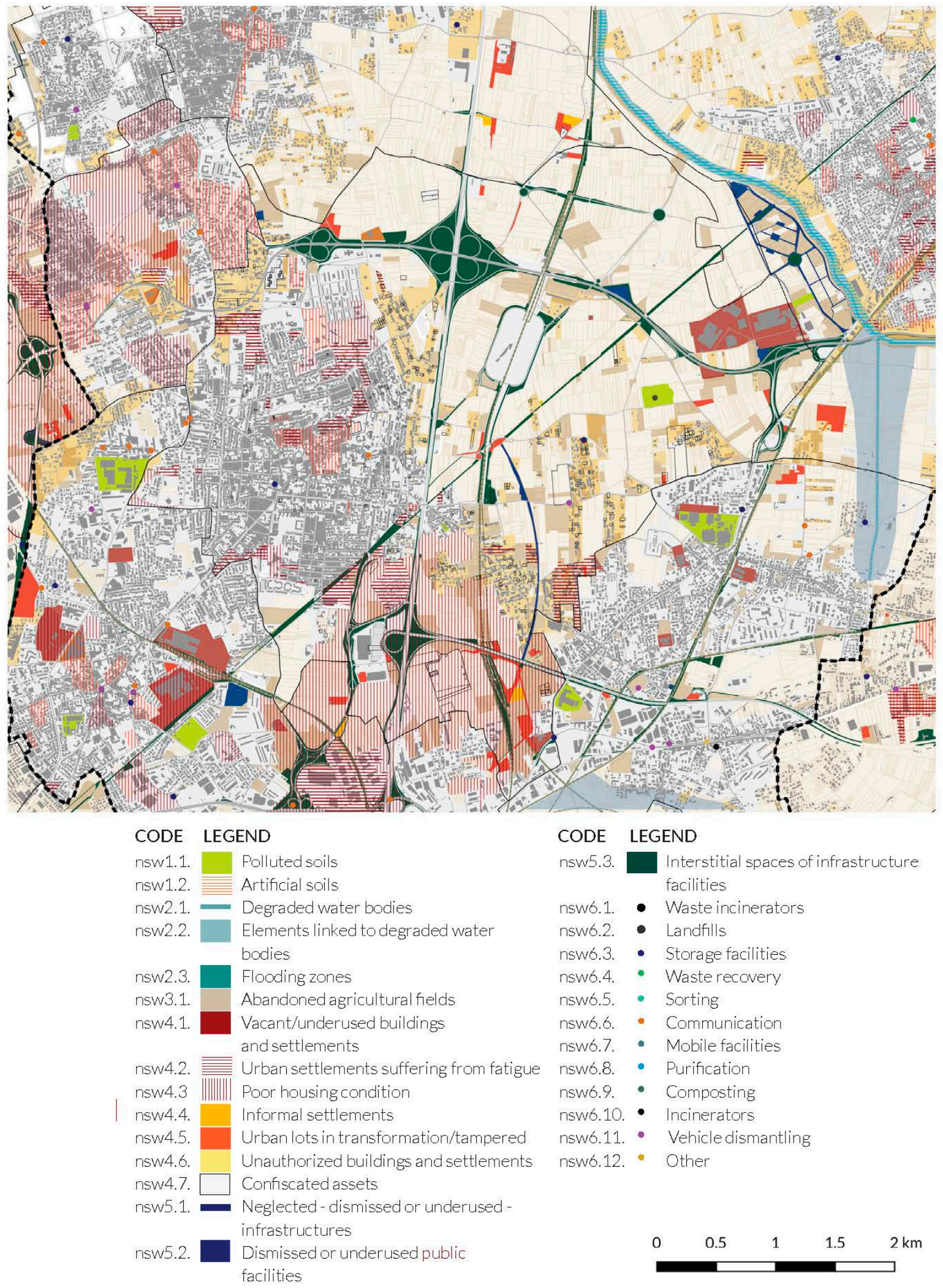

Figure 7. Wastescapes. Analytical description. Sample area of the case-study of Naples (Municipalities of Afragola, Acerra, Caivano, Casalnuovo di Napoli). Source: REPAiR Deliverable 3.3 "Process model for the two pilot cases", Annex 2, p.33, UNINA Lab REPAiR Team. 


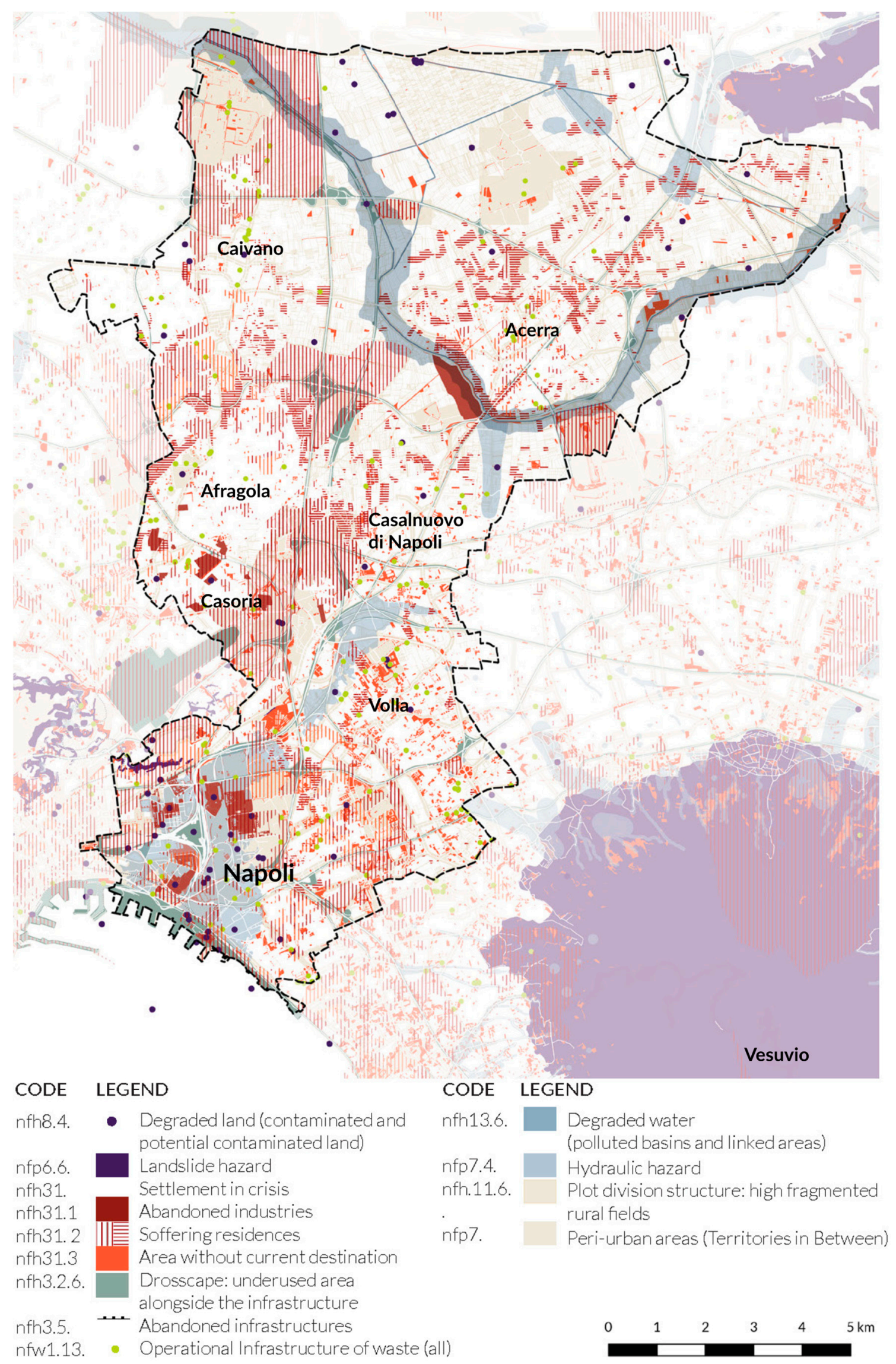

Figure 8. Naples wastescapes map. Source: REPAiR Deliverable 3.3 “Process model for the two pilot cases", Annex 2, p.30, UNINA Lab REPAiR Team. 
In the PULL of Naples, the lack of knowledge about circularity emerged on both institutional and local levels. It was found that there had been the need overcome the lack of confidence from communities and the private sector towards the possibility to develop the needed Eco-Innovative Solutions (EIS) to help the push towards circularity. In order to fill this gap of knowledge, and to cope with the above-mentioned mistrust, a series of informative meetings on the investigated topic had been organized at the beginning of the PULL process. This had been done in order to create a common understanding about the need for a paradigm change towards a circular regeneration of wastescapes. The EIS for the case of Naples are mainly aimed to look for better synergies [33] that can improve the spatial configuration of both the territory and waste management in its peri-urban areas.

Some of the proposed solution paths brought into focus the public purchase of illegal settlements, and the re-conversion of misused areas into public spaces and/or facilities which have been made available to the local communities. The solutions to these issues indicated an aim to involve cultural associations to manage communal areas, which would allow for the increase in the citizens' sense of belonging to this territory.

\subsubsection{Wastescapes in the Amsterdam Metropolitan Area}

For the Amsterdam case-study, the wastescapes identified within the focus area are included in the peri-urban territory of the Amsterdam Metropolitan Area (Figure 9). This area is located in the Northern part of the Randstad region, between the two provinces of North-Holland and Flevoland. The focus area includes Amsterdam, as well as the 32 municipalities adjacent to it, with a total population of about 2.4 million inhabitants [20].

In this territory, the main challenges are related to the redevelopment of the wastescapes around the Schiphol airport, which are now subject to construction restrictions due to noise and safety regulations. Another focus area in which problems exist are the polluted areas within the harbor, which are in dire need for re-programming towards new uses. These new functions can be defined as post-oil landscapes [90], namely in present and future wastescapes, making the need for finding Eco-innovative Solutions an urgent matter in these areas.

In addition, a key topic regarding the above-mentioned issues is related to the abilities of trust and collaboration among stakeholders that are necessary for the regeneration of wastescapes. These actions can be promoted through the creation of guidelines that allow for the transfer of knowledge developed from the collaborative environments of the Peri-urban Living Labs, to the interested public and private actors.

The mapping exercise to identify wastecapes in the AMA region aimed to overcome the classic definition of wasteland, primarily related to contaminated sites, also known as brownfields. Wastescapes have a broader definition, and represent different types of neglected, wasted, and underused spaces. There are in fact multiple variations of these types of spaces, such as "contaminated land, transport safety and noise areas (in the territory of the airport), contaminated waterbodies, infrastructures, abandoned buildings, land and industries, unused greenfields next to the infrastructure itself, and the operational infrastructure of waste" [22] (p. 56).

The participants in the PULL workshops of the AMA included researchers, local government representatives, policy makers, and local business representatives. A series of collaborative workshops have been held with the aim to develop EIS for a more Circular Economy in the AMA.

Firstly, the challenges of the case study area have been identified, due in part to the process defined by the 'challenge tree methodology.' Secondly, the objectives that need to respond to the specific challenges have been verified and ranked with the selected stakeholders. With the objectives laid out, there was a need to be able to develop preliminary EIS. During the various workshops, participants had been provided with EIS pre-complied templates (easy to be filled), which allowed them to work together. Most of the EIS for the PULL of the AMA focused mostly on objectives related to wastescapes, food waste, and construction and demolition waste. 


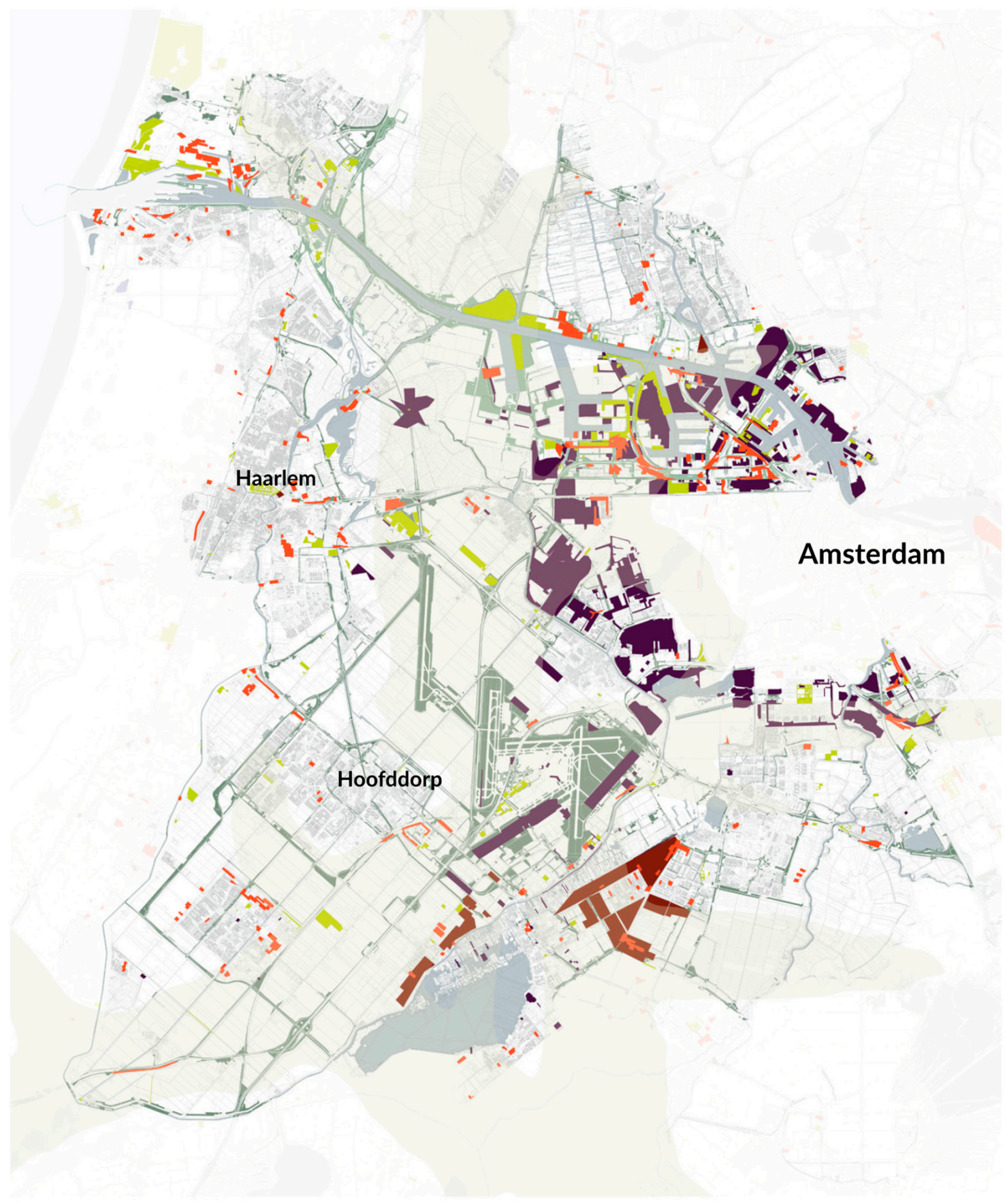

\section{LEGEND}

\section{$2 \mathrm{~km} L$}

afh 8.4 Degraded land (contaminated and potential contaminated land) afh31. Settlement in crisis (abandoned and underused building- industries) afh33. Settlement in crisis: Area without current destination afh 3.2.9 Drosscape: underused area along side the infrastructure

afh1.13. Operational Infrastructure of waste (landfill, incenerator, biodigestor, recycling facility) afh13.6. Degraded water (polluted basins and linked areas) afh3.6. safety and noise area of transport infrastructure afh3.11.6. As background the plot division structure

Figure 9. Amsterdam wastescapes map. Source: REPAiR Deliverable 3.3 "Process model for the two pilot cases", p. 57, Furlan C. et al., TUD REPAiR Team, UTJ_MapLab, 2018. 
As an example, some of the solution paths proposed for overcoming the problem of construction restrictions for the regeneration of wastescapes in the (buffer) areas around Schiphol airport are related to the necessity to improve the flexibility in regulations. This can be done by looking for noise-absorbing building materials, and/or increasing the ecological value of the area by developing a natural reserve within the airport noise contour area.

\section{Discussion}

This paper has discussed the possibility to consider not only material waste, but also discarded territories as resources that can improve the socio-ecological value of peri-urban areas, operationalizing a more inclusive Circular Economy. The regeneration of wastescapes is central to achieving this aim, which should result in an improved quality of life for all stakeholders involved. This approach, not yet widely applied at an institutional and formal level, has the potential to be tested globally in various urbanized contexts. The foundation of this approach is based on the trend that expects the majority of the people on the planet to be living in cities in the near future, within a context of resource scarcity and a multi-national agenda towards zero waste agendas.

Eco-Innovative Solutions (EIS) for wastescape regenerations can be developed through a co-creation process within territorial Peri-Urban Living Labs (PULLs) [20,33], where the complexity of the problems can be addressed. EIS are designed according to a framework that will eventually allow the inputting and testing of the solutions within a Geodesign Decision Support Environment [42]. The set of Eco-Innovative Solutions (responding to the question 'What?') and strategies (responding to the question 'How?') constitute a 'Change Model' [83] in which a transition towards a more Circular Economy can be achieved.

The wastescapes mapping exercise held in the PULLs help with identifying the sets of Eco-Innovative Solutions and Strategies which could theoretically be implemented. This is due in part to interviews and collective discussions, as well as thorough desk research and co-creation sessions with local stakeholders collaborating within the PULLs (e.g., municipalities, regional authorities, etc.) $[20,33]$. Hence, even if the final aim is to develop transferable EIS, they contain place-specific components that are related to the local challenges in the area. In addition, different disciplines and interests are represented in the structure of the PULLs, and the systemic changes required for the regeneration of wastescapes can be correctly addressed.

Wastescapes are considered as the outcome of the urban metabolism processes where socio-economic, spatial, and material dynamics are interwoven [22]. They are also constituted by 'Drosscape' [91], and 'Operational infrastructure of waste' [67], both referring to open spaces, as well as built entities and infrastructures.

Being a relatively unexplored concept, the term 'wastescapes' still needs a common definition, as well as a methodology for their identification and mapping. More importantly, the term needs to be widely shared in literature, and applied in policy documents. Therefore, this research aims to bridge this gap [20-22] by introducing the following four operational steps that are necessary for finding solutions to wastescapes:

- Firstly, researchers need to identify and map wastescapes in accordance with their knowledge, due in part to information gained in fieldtrips.

- Secondly, the research team needs to meet relevant stakeholders and key actors within the PULLs to refine the wastescape maps. By doing so, their specific knowledge and familiarity with the focus area will enlighten specific problems and challenges that characterize the area. Different methodologies such as challenge and problem trees are used towards this purpose.

- Thirdly, the mapping exercise of wastescapes needs to be finalized by the researchers (desk research).

- Fourthly, local stakeholders are called yet again to identify what the strategies to regenerate wastescapes are, and who are the key actors that should be involved for the implementation of the eco-innovation. In this phase, Eco-Innovative Solutions (EIS) are co-created addressing the 
Political/organisational (P), Economic, Societal (E), Technical (T), Environmental (E), and Legal (L) dimensions of the PESTEL framework.

Generally, the regeneration of wastescapes, in relation with the management of waste, poses huge environmental (i), governmental (ii), and social (iii) challenges to urbanists, urban designers, and to the key stakeholders involved in the decision-making processes.

(i) The environmental challenges can contribute to the slowdown of the regeneration of wastescapes, which can be related to the high costs necessary for soil reclamation. During the time frame of the soil reclamation, several uses are not allowed by law, such as noise or odor contours, while some uses are incompatible by law.

(ii) The governmental challenges can be related to the lack of regulations which could allow for temporary and flexible use of wastescapes. In addition, the regeneration of illegal/informal settlements or abandoned areas require costly and complex processes, including difficulties in the management of construction and demolition waste.

(iii) Social challenges concern the abandonment of public/private spaces, combined with a lack of adequate services and infrastructures, leading to a lack of safety for the inhabitants, and therefore creating mistrust towards institutions.

In summary, wastescapes can be considered as experimental areas that help with 'enabling contexts', [22] where developing innovation is combined with the engagement of all stakeholders. Vulnerable and disadvantaged groups of citizens (e.g., unemployed, refugee, etc.) can also be involved in this process of regeneration, allowing for the implementation of a more sustainable future and Circular Economy.

\section{Conclusions}

Throughout this article, we have emphasized the importance to extend the definition of waste to the discarded, forgotten, polluted, or heavily infrastructured areas of today's territories: the wastescapes. Wastescapes are characterized by complexity, since they involve different social, economic, environmental, and other related challenges and dimensions. However, this research shows that the implementation of a more circular economy requires the consideration of wastescapes as spatial resources. This represents a fundamental step to overcome the problems related to both resource scarcity and spatial fragmentation.

We have seen that peri-urban areas are particularly affected by the problem of wastescapes. This is because they are spatially fragmented territories, being characterized by mixed uses, and different functions scattered in the areas in-between urban and rural landscapes.

In this paper, circularity, even if it is based on the shared principles of Circular Economy, is outlined in a more holistic way by including a spatial dimension to it. This goes beyond material waste management, as the circular approach addressed here intends to deepen the physical interrelations and functional interdependencies within the contemporary urban condition. Moreover, the spatial implications of a circular management of waste and wastescape is investigated at the urban and territorial scale.

The in-depth definition of wastescapes provided in this study was utilized, and further verified, for a mapping exercise in two pilot cases: the metropolitan areas of both Amsterdam and Naples. This process had been conducted in Peri-urban Living Lab (PULLs) environments where different stakeholders are invited to work together in co-creation sessions. The aim of the two pilot PULLs was to first understand the challenges related to the areas. Secondly, to identify the related objectives and prioritize them, and then to eventually design the Eco-Innovative Solutions and strategies for waste management and wastescapes.

The Eco-Innovative Solutions and strategies, developed within the PULLs, work at a systemic level. This is because they have the aim to solve the current situation of economic, social, and landscape crises, 
as well as to face the inevitable scarcity of natural resources. In order to solve this, public/private partners, researchers, and students are all involved in the activities of the PULLs. This is done to implement EIS for both waste and wastescapes through a co-creation process. In the PULLs, the preference of all the stakeholders are taken into consideration for the development of well thought out solutions and strategies.

Although it still needs to be applied widely, the circular regeneration of wastescapes allows for the potential to close various loops of resource flows. Doing so will allow for the activation of an alternative kind of urban re-development, through the actions and problem solving of local communities around site-specific issues.

In conclusion, the spatial challenges related to resource scarcity, waste production, and urban encroachment on high-quality soils demonstrate the need for circular regeneration of wastescapes as an innovative process that can eventually lead to healthier cities with a higher quality of life.

Author Contributions: All the parts of this paper, including the reviewed versions of it, have been written and approved by both the authors: L.A. and A.v.T.; Writing-Review \& Editing, L.A., A.v.T.; Supervision, A.v.T.; Project Administration, A.v.T.; Funding Acquisition, REPAiR project.

Funding: This research is done within the framework of the European Horizon 2020 funded research 'REPAiR: REsource Management in Peri-urban AReas: Going Beyond Urban Metabolism'. This project has received funding from the European Union's Horizon 2020 research and innovation programme under grant agreement No 688920. This article reflects only the author's view. The Commission is not responsible for any use that may be made of the information it contains.

Acknowledgments: Thanks to the whole REPAiR Team. In particular to UNINA and TUDelft Research Teams. Special thanks to the AMS Institute for their share in the project, and in particular the Amsterdam case related work on wastescapes. Thanks to the students' team of the R \& D Studio: Spatial Strategies for Global Metropolis Q3 MSc 2 Urbanism, of TU Delft: Anubhuti Chandna, Danny Janse, Gwenhwyfar Spil, Jingxuan Xie, Osman Ural for some of the graphics included in this paper.

Conflicts of Interest: The authors declare no conflict of interest.

\section{References}

1. Unhabitat for a Better Urban Future Land. Available online: https://unhabitat.org/land/ (accessed on 19 November 2018).

2. Henriquez, L.; van Timmeren, A. Under Pressure: Water and the City; TU Delft \& AMS Institute: Delft/Amsterdam, The Netherlands, 2017; ISBN 978-94-6186-860-2.

3. McDonough, W.; Braungart, M. Cradle to Cradle: Remaking the Way We Make Things; Vintage: London, UK, 2008; ISBN 9780099535478.

4. UN. Resolution Adopted by the General Assembly on 25 September 2015. Transforming Our World: The 2030 Agenda for Sustainable Development; United Nations: New York, NY, USA, 2015.

5. Chen, J. Rapid Urbanization in China: A real challenge to soil protection and food security. Catena 2007, 69, 1-15. [CrossRef]

6. Tan, M.; Li, X.; Xie, H.; Lu, C. Urban land expansion and arable land loss in China-a case study of Beijing-Tianjin-Hebei region. Land Use Policy 2005, 22, 187-196. [CrossRef]

7. Fazel, S. Urban expansion and loss of agricultural land-a GIS based study of Saharanpur City, India. Environ. Urban. 2000, 12, 133-149. [CrossRef]

8. Pandey, B.; Seto, K.C. Urbanization and agricultural land loss in India: Comparing satellite estimates with census data. J. Environ. Manag. 2014. [CrossRef] [PubMed]

9. López, T.M.; Aide, T.M.; Thomlinson, J.R. Urban expansion and the loss of prime agricultural lands in Puerto Rico. Ambio 2001, 30, 49-54. [CrossRef] [PubMed]

10. Haase, J.E.; Lathrop, R.G. Land resource impact indicators of urban sprawl. Appl. Geogr. 2003, 23, 159-165. [CrossRef]

11. Worldometers. Countries in the World by Population. 2018. Available online: http://www.worldometers. info/world-population/population-by-country/ (accessed on 19 November 2018). 
12. Bruinsma, J. The Resource Outlook to 2050: By How Much Do Land, Water and Crop Yields Need to Increase by 2050? In Proceedings of the FAO Expert Meeting "How to Feed the World in 2050", Rome, Italy, 24-26 June 2009.

13. Bren d'Amour, C.; Reitsma, F.; Baiocchi, G.; Barthel, S.; Güneralp, B.; Erb, K.-H.; Haberl, H.; Creutzig, F.; Seto, K.C. Future urban land expansion and implications for global croplands. Proc. Natl. Acad. Sci. USA 2017, 114, 8939-8944. [CrossRef]

14. Godfray, H.C.J.; Beddington, J.R.; Crute, I.R.; Haddad, L.; Lawrence, D.; Muir, J.F.; Pretty, J.; Robinson, S.; Thomas, S.M.; Toulmin, C. Food Security: The Challenge of Feeding 9 Billion People. Science 2010, 327, 812-818. [CrossRef]

15. IPCC. Climate Change 2014: Synthesis Report; Contribution of Working Groups I, II and III to the Fifth Assessment Report of the Intergovernmental Panel on Climate Change; Core Writing Team, Pachauri, R.K., Meyer, L.A., Eds.; IPCC: Geneva, Switzerland, 2014.

16. Van Timmeren, A.; Henriquez, L.; Reynolds, A. ReciproCities. A Dynamic Equilibrium; Delft University of Technology (TUD): Delft, The Netherlands, 2013; ISBN 978-94-6186-256-3.

17. Amenta, L. Reverse Land Wasted Landscapes as a Resource to Re-Cycle Contemporary Cities; University of Naples Federico II: Napoli, Italy, 2015.

18. Palestino, M.F. Per un'agenda radicale della Terra dei Fuochi. CRIOS Critica degli Ordinamenti Spaziali 2015, 10, 9-19.

19. Amenta, L.; Attademo, A. Circular wastescapes. Waste as a resource for periurban landscapes planning. CRIOS 2016, 12, 79-88. [CrossRef]

20. REPAiR. PULLs Handbook REPAiR Deliverable 5.1; EU Commission Participant Portal: Brussels, Belgium, 2017. [CrossRef]

21. REPAiR. Introduction to Methodology for Integrated Spatial, Material Flow and Social Analyses REPAiR Deliverable 3.1; EU Commission Participant Portal: Brussels, Belgium, 2017. [CrossRef]

22. REPAiR. Process Model for the Two Pilot Cases: Amsterdam, The Netherlands E Naples, Italy. Deliverable 3.3; EU Commission Participant Portal: Brussels, Belgium, 2018.

23. De Leo, D.; Lieto, L.; Palestino, M.F. La sottorappresentazione della sregolazione. Un problema di definizioni e di policies. In Ripensare la questione urbana. Regionalizzazione dell'urbano in Italia e scenari di innovazione; Balducci, A., Fedeli, V., Curci, F., Eds.; Guerini e Associati editore: Milano, 2017; pp. 229-255.

24. De Leo, D.; Palestino, M.F. S-regulation matters. In Post-Metropolitan Territories. Looking for a New Urbanity; Balducci, A., Fedeli, V., Curci, F., Eds.; Routledge: London, UK; New York, NY, USA, 2017; pp. $274-280$.

25. AMS. Amsterdam Institute for Advanced Metropolitan Solutions (AMS Institute) Research and Valorisation Programme outline 2015-2018; Amsterdam Institute for Advanced Metropolitan Solutions (AMS Institute): Amsterdam, The Netherlands, 2015.

26. Kennedy, C.; Pincetl, S.; Bunje, P. The study of urban metabolism and its applications to urban planning and design. Environ. Pollut. 2011, 159, 1965-1973. [CrossRef] [PubMed]

27. Kennedy, C.; Cuddihy, J.; Engel-Yan, J. The changing metabolism of cities. J. Ind. Ecol. 2007, 11, 43-59. [CrossRef]

28. Pincetl, S.; Bunje, P.; Holmes, T. An expanded urban metabolism method: Toward a systems approach for assessing urban energy processes and causes. Landsc. Urban Plan. 2012, 107, 193-202. [CrossRef]

29. Van Timmeren, A. The Concept of the Urban Metabolism (UM); Environmental Technology \& Design, Department of Urbanism, Faculty of Architecture, Delft University of Technology: Delft, The Netherlands, 2014.

30. Wolman, A. The Metabolism of Cities. Sci. Am. 1965, 213, 178-190. [CrossRef]

31. Steen, K.; van Bueren, E. Urban Living Labs. A Living Lab Way of Working; Amsterdam Institute for Advanced Metropolitan Solutions, Delft University of Technology: Delft, The Netherlands, 2017.

32. EC. Innovation for a Sustainable Future-The Eco-Innovation Action Plan (Eco-AP); European Commission: Brussels, Belgium, 2011.

33. REPAiR. Handbook: How to Run a PULL Deliverable 5.4; EU Commission Participant Portal: Brussels, Belgium, 2018.

34. JRC. The State of Soil in Europe: A Contribution of the JRC to the European Environment Agency's Environment State and Outlook Report-SOER 2010; Publications Office of the European Union: Luxembourg, 2012.

35. Krekel, C.; Kolbe, J.; Wüstemann, H. The greener, the happier? The effect of urban land use on residential well-being. Ecol. Econ. 2016, 121, 117-127. [CrossRef] 
36. Building Sustainable Cities of the Future; Bishop, J. (Ed.) Springer International Publishing: Cham, Switzerland, 2017.

37. Benton-Short, L.; Short, J.R. Cities and Nature. Critical Introductions to Urbanism and the City, 2nd ed.; Routledge: London, UK, 2013; ISBN 9780415625562.

38. Alexander, C. A city is not a tree. In Design After Modernism: Beyond the Object; Thachara, J., Ed.; Thames and Hudson: London, UK, 1988; pp. 67-84.

39. Donadieu, P. Campagnes Urbaines; Actes Sud/E.N.S.P. Arles-Versailles. Ecole nationale superieure du paysage: Arles, France, 1998; ISBN 27427202359782742720231.

40. Viganò, P. Territori della Nuova Modernità Provincia di Lecce, Assessorato alla Gestione Territoriale: Piano Territoriale di Coordinamento = Territories of a New Modernity; Electa: Napoli, Italy, 2001.

41. Wandl, A.; Nadin, V.; Zonneveld, W.; Rooij, R. Beyond urban-rural classifications: Characterising and mapping territories-in-between across Europe. Landsc. Urban Plan. 2014, 130, 50-63. [CrossRef]

42. EC. Grant Agreement n. NUMBER -688920, 'REPAiR: REsource Management in Peri-Urban AReas: Going beyond Urban Metabolism'; EU Commission Participant Portal: Brussels, Belgium, 2016.

43. EEA (European Environment Agency). Environmental challenges in Europe and in the rest of the world are intertwined. In The European Environment I State and Outlook 2010; European Environment Agency (EEA): Copenhagen, Denmark, 2010.

44. Berger, A. Drosscape: Wasting Land in Urban America; Princeton: New York, NY, USA, 2006; ISBN 1568987137.

45. Global Footprint Network. Ecological Footprint. Available online: https://www.footprintnetwork.org/ourwork/ecological-footprint/ (accessed on 19 November 2018).

46. Global Footprint Network. 2006 Annual Report; Global Footprint Network: Oakland, CA, USA, 2006.

47. FAO (Food and Agriculture Organization). Soil Is a Non-Renewable Resource. Its Preservation Is Essential for Food Security and Our Sustainable Future. Available online: http:/ / www.fao.org/resources/infographics/ infographics-details/en/c/278954/ (accessed on 15 November 2017).

48. EC. Thematic Strategy for Soil Protection; COM(2006) 231 Final, Europese Commissie: Brussel, Belgium, 2006.

49. Gasparrini, C.; Terracciano, A. Dross City. Metabolismo Urbano, Resilienza e Progetto di Riciclo dei Drosscape; LISt Lab: Rovereto, Italy, 2016; ISBN 978-8899854232.

50. Girardet, H. Regenerative Cities; World Future Council/HafenCity University Hamburg (HCU) Commission on Cities and Climate Change: Hamburg, Germany, 2010.

51. Corner, J. Organizational Ecologies. In Going Live, from States to Systems; Princeton Architectural Press: New York, NY, USA, 2015; ISBN 978-1616893613.

52. REDD. Multistakeholder Processes. Available online: http://www.redd-standards.org/key-issues/ multistakeholder-process (accessed on 15 November 2017).

53. University Wageningen. Multi-Stakeholder Partnership Portal. Available online: http://www.mspguide. org/ (accessed on 15 November 2017).

54. EEAC Network. Europe Goes Circular. Challenges in the Transition to a Circular Economy; EEAC Network Foundation: The Hague, The Netherlands, 2018.

55. Mininni, M. Prefazione. In Pierre Donadieu. Campagne Urbane. Una Nuova Proposta di Paesaggio della Città; Donzelli Editore: Roma, Italy, 2006.

56. Indovina, F.; Doria, L.; Fegolent, L.; Savino, M. Dalla Città Diffusa All'arcipelago Metropolitano; Franco Angeli: Roma, Italy, 2009; ISBN 9788856811704.

57. Soja, E. Postmetropolis: Critical Studies of Cities and Regions; Wiley-Blackwell Publishers: Oxford, UK, 2000; ISBN 978-1-577-18001-2.

58. Pasqui, G. Urbanistica Oggi Piccolo Lessico Critico; Donzelli Editore: Roma, Italy, 2017; ISBN 9788868436582.

59. EC. Eco-Innovation the Key to Europe's Future Competitiveness; European Commission: Brussels, Belgium, 2012.

60. EC. Eco-Innovation at the Heart of European Policies. Available online: https:/ / ec.europa.eu/environment/ ecoap/about-action-plan/objectives-methodology (accessed on 19 November 2018).

61. Formato, E.; Attademo, A. NO.WALL:S. Un progetto di rigenerazione, per l'ospitalità e la condivisione. Territorio 2017, 81, 129-139. [CrossRef]

62. FRINGE SHIFTS. Transforming Planning for New Sub>urban Habitats; Attademo, A., Formato, E., Eds.; LISTLab: Barcellona, Spain, 2018; ISBN 9788899854300.

63. Cerreta, M.; Panaro, S. From Perceived Values to Shared Values: A Multi-Stakeholder Spatial Decision Analysis (M-SSDA) for Resilient Landscapes. Sustainability 2017, 9, 1113. [CrossRef] 
64. Cerreta, M.; Panaro, S. The Co-evaluation Approach: Synergistic and Adaptive Decision-making Processes for Community-led Local Innovation. In Smart Landscapes. Hybrid Decision-Making Processes for the Spatial Innovation. ABITARE IL FUTURO; Clean: Napoli, Italy, 2017; pp. 279-290. ISBN 978-88-8497-497-6.

65. Lynch, K. Wasting Away; Sierra Club Books: Oakland, CA, USA, 1990; ISBN 9780871566751.

66. Council of Europe. Landscape Convention. Available online: https://www.coe.int/en/web/landscape (accessed on 19 November 2018).

67. Implosions/Explosions: Towards a Study of Planetary Urbanization; Brenner, N. (Ed.) Jovis: Berlin, Germany, 2014; ISBN 978-3-86859-317-4.

68. Ghosn, R.; Jazairy, E.H. Geographies of Trash; Actar Publishers: New York, NY, USA, 2015; ISBN 978-1-940291-64-2.

69. Koolhaas, R. Junkspace; Quodlibet Architettura: Macerata, Italy, 2006; ISBN 9788874621125.

70. Clément, G. Manifesto del Terzo Paesaggio; Quodlibet: Macerata, Italy, 2005; ISBN 88-7462-048-9.

71. Biodiversity. Information System for Europe Pollution. Available online: https://biodiversity.europa.eu/ topics / pollution (accessed on 19 November 2018).

72. Zanotto, F.; Amenta, L. Verso l'Economia Circolare come Strumento di Pianificazione. Il Caso Olandese. In Conference Proceedings: Un futuro Affidabile per la Città, Urban Promo 2017, Section 4 Strategie di Adattamento al Cambiamento Climatico; Urbanpromo: Milano, Italy, 2017.

73. Bonomi, A.; Della Puppa, F.; Masiero, R. La Società Circolare. Fordismo, Capitalismo Molecolare, Sharing Economy; DeriveApprodi: Rome, Italy, 2016; ISBN 9788865481653.

74. Fussler, C.; James, P. Driving Eco-Innovation: A Breakthrough Discipline for Innovation and Sustainability; Pitman Publishing: London, UK, 1996; ISBN 0273622072-9780273622079.

75. David, P.A. Clio and the Economics of QWERTY. Am. Econ. Rev. 1985, 75, 332-337.

76. David, P.A. Path Dependence-A Foundational Concept for Historical Social Science. J. Hist. Econ. Econom. Hist. 2007, 1, 91-114. [CrossRef]

77. Mahoney, J. Path dependence in historical research. Theory Soc. 2000, 29, 507-548. [CrossRef]

78. EC. Biodiversity and Ecosystem Services. Available online: https://ec.europa.eu/europeaid/sectors/ environment/biodiversity-and-ecosystem-services_en (accessed on 19 November 2018).

79. EC. The EU Biodiversity Strategy to 2020; Publications Office of the European Union: Luxembourg, 2011; ISBN 978-92-79-20762-4.

80. Unmüßig, B.; Töpfer, K. Introduction. In Soil Atlas. Facts and Figures about Earth, Land and Fields; Chemnitz, C., Weigelt, J., Eds.; Heinrich Böll Foundation: Berlin, Germany, 2015.

81. Ellen MacArthur Foundation. Urban Biocycles; Ellen MacArthur Foundation: Isle of Wight, UK, 2017.

82. Webb, R.; Bai, X.; Smith, M.S.; Costanza, R.; Griggs, D.; Moglia, M.; Neuman, M.; Newman, P.; Newton, P.; Norman, B.; et al. Sustainable urban systems: Co-design and framing for transformation. Ambio 2018, 47, 57-77. [CrossRef] [PubMed]

83. Steinitz, C. A Framework for Geodesign. Changing Geography by Design; Esri Press: New York, NY, USA, 2012; ISBN 9781589483330.

84. Professional Academy. Marketing Theories-Pestel Analysis. Available online: https://www. professionalacademy.com/blogs-and-advice/marketing-theories---pestel-analysis (accessed on 19 November 2018).

85. Ståhlbröst, A.; Holst, M. The Living Lab Methodology Handbook; Social Informatics at Luleå University of Technology/CDT_Centre for Distance-Spanning Technology: Luleå, Sweden, 2012.

86. Core Labs. Building Sustainable Competitiveness Living Labs Roadmap 2007-2010 Recommendations on Networked Systems for Open User; Luleå University of Technology/Centre for Distance-Spanning Technology: Luleå, Sweden, 2007.

87. Voytenko, Y.; McCormick, K.; Evans, J.; Schliwa, G. Urban living labs for sustainability and low carbon cities in Europe: Towards a research agenda. J. Clean. Prod. 2016, 123, 45-54. [CrossRef]

88. UNEP. Decoupling Natural Resource Use and Environmental Impacts from Economic Growth: A Report of the Working Group on Decoupling to the International Resource Panel; Fischer-Kowalski, M., Swilling, M., von Weizsäcker, E.U., Ren, Y., Moriguchi, Y., Crane, W., Krausmann, F., Eisenmenger, N., Giljum, S., Hennicke, P., et al., Eds.; United Nations Environment Programme: Nairobi, Kenya, 2011.

89. REPAiR. First Application of the Decision Model in All Case Studies Deliverable 6.4; EU Commission Participant Portal: Brussels, Belgium, 2018. 
90. Hein, C. Between oil and water. In The Logistical Petroleumscape; Bhatia, N., Casper, M., Eds.; Actar Publishers \& Architecture at Rice: New York, NY, USA, 2013.

91. Berger, A. Drosscape. In The Landscape Urbanism Reader; Princenton Architectural Press: New York, NY, USA, 2006; pp. 198-217. 